\title{
CONTENIDOS URBANÍSTICOS EN LA CARRERA DE ABOGACÍA DE LA UNIVERSIDAD NACIONAL DEL LITORAL (ARGENTINA, 1920-1948)
}

DOI: http://dx.doi.org/10.1590/2236-3459/63052

\author{
Norma Elizabeth Levrand \\ Universidad Nacional del Litoral, Argentina.
}

$\cos 80$

\begin{abstract}
Resumen
Los contenidos de urbanismo no fueron ampliamente tratados en los programas de Derecho en Argentina, sin conformar hoy el curriculum de la carrera. Sin embargo, en la Universidad Nacional del Litoral, en las primeras décadas del siglo 20, Alcides Greca, prototipo de intelectual urbanista, buscó desarrollar en el ámbito académico estos contenidos e, incluso, traducirlos en el currículum de enseñanza. El objetivo de este trabajo es presentar las relaciones entre Alcides Greca y otros actores involucrados en la enseñanza del urbanismo de la época (1920-1948), a fin de describir el impacto que dicha relación y formación intelectual tuvieron en la inclusión de estos contenidos en la carrera de Derecho.

Palabras-clave: urbanismo, intelectual, currículum de enseñanza, Derecho.
\end{abstract}

\section{CONTEÚDOS URBANÍSTICOS NO CURSO DE DIREITO DA UNIVERSIDADE NACIONAL DO LITORAL (ARGENTINA, 1920-1948)}

Resumo

Os conteúdos relacionados ao urbanismo não foram amplamente tratados nos programas dos cursos de Direito na Argentina, assim como não integram hoje o currículo do curso. No entanto, na Universidad Nacional del Litoral, nas primeiras décadas do século 20, Alcides Greca, um protótipo intelectual, procurou desenvolver este conteúdo e até mesmo traduzi-lo no currículo de ensino. $O$ objetivo deste trabalho é apresentar as relações entre Alcides Greca e outros atores envolvidos no processo de ensino do urbanismo, entre 1920 e 1948, para descrever o impacto que esta relação teve na formação intelectual e a inclusão destes conteúdos na licenciatura em Direito.

Palavras-chave: urbanismo, intelectual, currículo de ensino, Direito. 


\title{
URBAN CONTENT IN THE DEGREE IN LAW OF NATIONAL UNIVERSITY OF LITORAL (ARGENTINA, 1920-1948)
}

\begin{abstract}
Urban planning contents were not widely dealt with in the Law syllabus in Argentina, and nowadays they are not part of them. However, during the first decades of the 20th century in the National University of the Littoral, Alcides Greca, who was a prototype of an intellectual urban planner, tried to develop these contents inside the academic scope, and he even tried to translate them into the teaching syllabus. The aim of this work is to introduce the relations between Alcides Greca and the other actors involved in the process of teaching urban planning during the period 1920-1948, trying to describe the impact that said relation and the intellectual training had on the inclusion of these contents in the Law university course.

Key-words: urban planning, intellectual, academic scope, Law.

\section{CONTENU DU DROIT DE L'URBANISME DANS LE DIPLOME DE L'UNIVERSITÉ NATIONALE DU LITORAL (ARGENTINE, 1920-1948)}

Résumé

Le contenu de l'urbanisme ont pas été largement couvertes par les programmes de droit en Argentine, et aujourd'hui lui n'formes part pas le programme de la course. Cependant, à I'Universidad Nacional del Litoral, dans les premières décennies du $20^{\mathrm{e}}$ siècle, Alcides Greca, développeur prototype intellectuelle, a cherché à développer ce contenu dans le cadre universitaire et même de les traduire dans le programme d'enseignement. Le but de cet article est de présenter les relations entre Alcides Greca et d'autres acteurs impliqués dans l'enseignement de l'urbanisme de la période (1920-1948), pour décrire l'impact que cette relation avait une formation intellectuelle et l'inclusion de ces contenus dans le diplôme en Droit.

Mot-clè: urbanisme, intellectuelle, programme d'enseignement, Droit. 


\section{La transmisión de conocimiento acerca de la ciudad en una facultad de derecho}

i bien podría situarse el nacimiento de las ciudades en la Grecia antigua, las modificaciones que fue sufriendo el concepto tienen un parapeto infranqueable a partir de la Revolución Industrial. Lo que denominamos ciudad en nuestros días es notoriamente distinto de las ciudades antiguas y medievales. El signo de la contemporaneidad está dado por un proceso de concentración de riquezas materiales y sociales, que le otorga un sello distintivo a esta dinámica. La ciudad atrae población porque contiene un potencial de riqueza (Sanchez, s/f), mas dicho potencial no siempre es apropiado por todos los actores en la misma medida. Así, en la ciudad se verifican las diversas estructuras sociales y sus posibilidades de acción con mayor densidad. Henry Lefebvre expresa en este sentido "la estructura social figura en la ciudad, y en ella se hace sensible y significa un orden. Inversamente, la ciudad es un fragmento del conjunto social; transluce, porque las contiene e incorpora en la materia sensible a las instituciones e ideologías" (Lefevbre, 1968, p. 78).

Esta complejidad manifiesta de las ciudades industriales fue objeto de problematización por un conjunto de gestores públicos que vieron la necesidad de reglar y establecer ciertos límites a la acción privada dentro de la ciudad, como así también garantizar un conjunto de derechos a los ciudadanos, en su carácter de tales. En el ámbito jurídico esta problematización surgió en la disciplina denominada Derecho Urbanístico. En Argentina, a comienzos del siglo 20 esta disciplina estaba poco explorada, y la regulación de estos aspectos estaba diseminada en normas de carácter nacional, como el Código Civil, y municipal, tales las normas referentes a autorizaciones de mercados concentradores, y precarias distribuciones funcionales dentro del éjido urbano. A ello sumado que a finales del siglo 19 y comienzos del siglo 20 , se definirán las nuevas ciudades por la posibilidad de contar con servicios públicos y, por ende, el Derecho del Urbanismo emergente se confundirá, muchas veces, con el derecho de la autoridad administrativa.

En este contexto, el examen de la obra de Alcides Greca, jurista e intelectual litoraleño, se afirma, primeramente en su biografía. Alcides Gregorio Greca nace el 13 de febrero de 1889 en San Javier, provincia de Santa Fe, Argentina. Realizó sus estudios optando por una educación laica ${ }^{1}$, y se recibió de abogado en 1917. Su producción periodística, literaria, cinematográfica, jurídica y sobre enseñanza sumadas a su desempeño político y universitario permiten catalogarlo en la tribu ${ }^{2}$ de los intelectuales. Entendidos como un grupo comprometido con las necesidades de la comunidad, y que pretende animar su discusión democrática partiendo de su disciplina pero superándola, apoyándose en su autoridad como hombres de cultura, fundados en su reputación como escritores, científicos, artistas o universitarios (Altamirano, 2013). Profundamente

\footnotetext{
${ }^{1}$ Alcides Greca recibe su primera educación y hace vida social junto a la comunidad aborigen mocoví. En 1903 ingresa al nivel secundario en la capital provincial, Santa Fe, en el Colegio de la Inmaculada Concepción, establecimiento a cargo de la Orden Jesuita. En 1907, decide cambiar y finaliza sus estudios secundarios en una escuela laica, el Colegio Nacional Simón de Iriondo, siendo egresado de la primera promoción de estudiantes.

2 Tomamos el calificativo del título publicado por Altamirano (2013).

\begin{tabular}{|l|l|l|r} 
Hist. Educ. (Online) & Porto Alegre & v. 21 & n. 51
\end{tabular}

$51 \quad$ Jan./abr., 2017

p. $419-434$
} 
relacionado con su realidad cercana, Alcides Greca pretendió transformarla a través de su contribución en los ámbitos mencionados. Particular interés reviste, en el ámbito de la Facultad de Ciencias Jurídicas y Sociales - FCJS - de la Universidad Nacional del Litoral su aporte como jurista en la problemática de las ciudades.

La producción de Alcides Greca, fundamentalmente las publicaciones realizadas en la Revista de la Facultad de Ciencias Jurídicas y Sociales, la Revista de Derecho y Administración Municipal y en la revista Universidad ${ }^{3}$, del desarrollo del Primer Congreso Argentino de Urbanismo y los programas curriculares, serán el insumo utilizado para visualizar la acción de este profesor y las relaciones del mismo con otros actores que problematizaban la enseñanza del urbanismo. Se pretende indagar, entonces, el espacio que ocuparon estos contenidos en la enseñanza jurídica en el período 1920-1948 en la FCJS de la Universidad Nacional del Litoral. El recorte temporal está dado por el período de mayor actividad del profesor Greca, atento que la indagación en planes de estudio históricos han dado como resultado que la figura de este docente ha sido notable en el desarrollo de los contenidos de enseñanza referidos.

En este sentido, el fuerte impacto que tuvo la temática urbanística provino fundamentalmente del carácter de intelectual de Alcides Greca. Este autor se relacionó con otros docentes que producían conocimientos y prácticas sobre el urbanismo que impactaron en la relevancia del área en la FCJS. A partir de ello, Greca promovió la formación e investigación especializadas, en una disciplina a la que vaticinaba "tener extraordinario desarrollo en el futuro" (Greca, 1937, p. 6).

\section{Vínculos en torno al urbanismo en la Universidad Nacional del Litoral}

En el ámbito de la Universidad Nacional del Litoral, las cuestiones relacionadas al estudio del urbanismo se desarrollaron en distintas unidades académicas.

Alcides Greca comienza su actividad académica en la FCJS el 26 de junio de 1920, fecha en que es nombrado profesor de Derecho Administrativo. En 1931 es autorizado a dictar un curso libre de Derecho Municipal Comparado, en el cual será nombrado profesor interino en 1934, profesor adjunto el 31 de julio de 1937 y profesor titular el 19 de septiembre de 1940. En octubre de 1935 es designado director de la Revista de la Facultad, cargo que ocupará hasta 1948, fecha en que renuncia al mismo. El 31 de julio de 1939, previa adhesión del Consejo Directivo de la Facultad al Congreso Panamericano de la Vivienda Popular, designa a Alcides Greca para que concurra en representación de esta Unidad Académica. Y el 20 de agosto de 1941 se hace lo propio con el Segundo Congreso Interamericano de Municipios.

Renuncia sus cargos en las cátedras de Derecho Administrativo y Derecho Municipal y Comparado de la Facultad de Ciencias Jurídicas y Sociales de la Universidad Nacional del Litoral el 20 de abril de 1948. Conforme los considerandos de la resolución, la misma se fundamenta en la opción por la cátedra de Derecho Administrativo en la Facultad de Ciencias Económicas, Comerciales y Políticas, que a la época funcionaba en la ciudad de Rosario.

\footnotetext{
${ }^{3}$ Todas estas publicaciones se realizaron en la Editorial de la Universidad Nacional del Litoral. \begin{tabular}{|l|l|l|l|l}
\hline Hist. Educ. (Online) & Porto Alegre & v. 21 & n. 51 & Jan./abr., 2017
\end{tabular} 
En poco más de un cuarto de siglo, Greca se relaciona con un conjunto de profesores preocupados por los problemas de la ciudad, y su regulación. Dentro del ámbito de la FCJS, este autor inlcuirá la temática en el curso de Derecho Municipal Comparado, logrando un desarrollo no igualado posteriormente de las herramientas jurídicas regulatorias de la ciudad.

En esta red, y dentro de la FCJS, además de los trabajos de Alcides Greca, es visible la influencia de José Lo Valvo, quien fuera decano de la FCJS (1932-1936). Además de escribir diversos artículos científicos al respecto, fue el autor del anteproyecto del Código del Urbanismo para la ciudad de Rosario. Bajo su decanato, fueron sancionadas por su iniciativa dos ordenanzas cuya finalidad era promocionar el urbanismo: una de ellas creaba el Instituto de Urbanismo y la otra implementaba la Semana del Urbanismo. Si bien no existen constancias de que dicho Instituto haya sesionado en el seno de la Facultad, la pesquisa resultó favorable para la Semana del Urbanismo. La misma se desarrolló en 1936 y fruto de la misma se publicaron los números 21 y 22 de la Revista de la Facultad de Ciencias Jurídicas y Sociales, aunque posteriormente no pudo determinarse en la investigación que se haya reiterado.

El vínculo entre Alcides Greca y José Lo Valvo fue el conductor más fuerte para el desarrollo de la investigación jurídica en la temática y promotor de las publicaciones sobre Urbanismo en la disciplina jurídica en el ámbito de la FCJS. Lo Valvo había ingresado como profesor de Introducción al derecho en 1921 y luego llegó a la posición de decano electo en 1932 jugando "un rol central en el Honorable Consejo Superior en aquellas discusiones llegando a formar y documentar un discurso institucional dotado de una estricta analítica, gran riqueza expositiva, sólida capacidad de defensa argumental" (Sozzo; 2012, s/p). El espacio de poder dentro de la gestión académica, aunado a su particular interés por la problemática urbana ${ }^{4}$ imprimieron a la relación entre ambos un matiz particular. Cuenta de ello dan las alusiones recíprocas que realizan sobre sus publicaciones ${ }^{5}$.

Asimismo, otros doctrinarios del derecho aportaban a la materia, entre los que se destacan Rafael Bielsa y Mariano Tissembaum. El primero fue un reconocido jurista dedicado al Derecho Administrativo. De gran influencia en la Facultad de Ciencias Económicas, Comerciales y Políticas de la Universidad Nacional del Litoral, la proyección nacional de su obra a partir de la década de 1940 arrastraría al Derecho Urbanístico a la arena del Derecho Administrativo. Por su parte, si bien tiene alguna contribución en el ámbito del Urbanismo ${ }^{6}$, Mariano Tissembaum se dedicó fundamentalmente al estudio del Derecho del Trabajo.

\footnotetext{
${ }^{4}$ A partir de su desempeño como concejal por la ciudad de Rosario, Lo Valvo desarrolla una serie de publicaciones que pretenden fundar la autonomía municipal y regular la ciudad. Entre ello se destaca el Anteproyecto de Código de Urbanismo (1938). En palabras de Sozzo: "Lo Valvo fue arquitecto de un manera de pensar un municipio fuerte, un municipio con una capacidad de intervención que lo acercaban a las potencialidades del Estado Provincial" (Sozzo; 2012, s/p).

${ }^{5}$ A modo ejemplificativo puede mencionarse que Alcides Greca prologa la obra La ciudad nueva de José Lo Valvo (1936); recíprocamente José Lo Valvo, al inaugurar los cursos del mismo año refiere a la labor de Greca respecto del urbanismo señalando que "el profesor de derecho municipal doctor Alcides Greca, por su parte, ha prestado al tema atención preferente" (Lo Valvo, 1936, p. 9).

${ }^{6}$ De hecho, en el rastreo de publicaciones, sólo encontramos referida al tema urbanístico La actividad industrial y su repercusión urbana, publicada en la Revista de la Facultad de Ciencias Jurídicas y Sociales, n. 21-22, 1937, p. 117. 
En otras unidades académicas, el tema también despertaba inquietudes. En la Facultad de Ciencias Médicas se destacaba el dr. Francisco Albornoz quien era profesor adjunto de la cátedra Higiene Médica y escribió el artículo La higiene de la ciudad de Rosario: deficiencias. Plan de higienización publicado en el año 1928 en la Revista Médica.

Por su parte, Francisco Bendicente, profesor de la Escuela Superior Nacional de Comercio de la Universidad Nacional del Litoral, fue contador general de la Dirección de Obras Públicas de Santa Fe y se especializó en el desarrollo de los servicios públicos.

En la Facultad de Ciencias Económicas, sobresalían: Elena Berjman, doctora en Ciencias Económicas y docente de la misma, quien publicó diversos trabajos entre los cuales merece ser mencionado Consideraciones sobre cálculo de la población; Natalio Muratti quien redactó Municipalización de los servicios públicos; Domingo Dall' Anese, quien fuera profesor de Transportes y Tarifas, y de Economía Política.

También merece destacarse el Ing. Carlos E. Diulefait, profesor de la Facultad de Ciencias Matemáticas y de la Facultad de Ciencias Económicas, quien fue autor de La función logística en la teoría de la población y La teoría de la población en relación con sus grupos sociales.

Finalmente, no puede dejar de distinguirse la especial contribución de Angel Guido, profesor titular de Arquitectura y Urbanismo en la Facultad de Ciencias Matemáticas quien realizó un aporte insoslayable al estudio de la problemática en el ámbito de la Universidad Nacional del Litoral, ubicándose como un referente interno y externo a la misma, con proyección internacional. Su formación académica, unida a la concepción urbanística que pregonaba - la formación de una especialización dentro de los arquitectos -, da a sus intervenciones un sesgo particular. Co-autor del Primer Plan Regulador de la Ciudad de Rosario, primero sancionado en nuestro país, fue el prototipo de experto al servicio del gobierno que inspiró la carrera de urbanista en la primera mitad del siglo 20 (Rigotti; 2012).

En rigor, el urbanismo como un saber específico se consolidó a partir de la Town Planning Conference de Londres en 1910. En ella se pretendía unificar las distintas aproximaciones disciplinares que se habían hecho desde la arquitectura, las ingenierías, la estadística, etc. En tal sentido, apunta Rigotti que en Argentina la aspiración a superar saberes y prácticas dispersas signó el primer instrumento del urbanismo: el Plan Regulador (Rigotti, 2012). El principal promotor de este instrumento técnico era el ingeniero Della Paolera, quien proponía que los municipios contrataran un experto a cargo del monitoreo de la fisiología urbana de manera permanente. Esta propuesta se plasmaría en las Oficinas del Plan de Urbanización de las ciudades de Buenos Aires y Mar del Plata. En lo cercano, la influencia de Della Paolera y Guido implicaría la actuación de arquitectos en carácter de gestores estatales de esta nueva problemática.

Hasta aquí puede visualizarse un conjunto de profesionales que abordaban, cada uno desde su disciplina, la cuestión urbanística y buscaban detectar problemas y proponer soluciones. Esta enumeración de referentes no pasaría de ser tal sin un efectivo intercambio entre ellos. Aquello que hoy denominamos multidisciplina ${ }^{7}$ fue amparado por

\footnotetext{
7 Tomamos la definición de Sotolongo y Delgado, entendiendo la multidisciplina como el esfuerzo indagatorio convergente de varias disciplinas diferentes hacia el abordaje de un mismo problema o situación a dilucidar (Sotolongo Codina; Delgado Díaz, 2006) 
las reuniones científicas que reunían a este grupo de investigadores y permitían su intercambio. Como se mencionó, Greca no sólo participaba de estas reuniones, incluso en carácter de representación de la FCJS, sino que formó parte de la organización de la Semana del Urbanismo, fruto de la cual se publicaron en la Revista de la Facultad de Ciencias Jurídicas y Sociales una serie de contribuciones que provenían de este grupo de investigadores dentro de la Universidad Nacional del Litoral. Esta publicación estuvo a cargo de Greca, quien en ese momento se desempeñaba como director de la revista.

\section{La regulación urbanística en la visión de Alcides Greca}

Este apartado esboza una breve caracterización de la concepción multidisciplinar que pregonaba Alcides Greca para abordar la problemática urbanística. A tal efecto es necesario narrar que durante el 1er. Congreso Argentino de Urbanismo (1935) se abordó como un tema especial las Previsiones del Urbanismo y dentro de éste, una serie de trabajos estuvo dedicada a la enseñanza del urbanismo. Dentro de sub-tema, y refiriéndose a la educación superior, un grupo de profesores pretendía la institución de un título de posgraduación para arquitectos en esta temática. Entretanto otro grupo pregonaba la inclusión de estos contenidos en la currícula de grado de las disciplinas que podrían tener injerencia en la misma, fundamentalmente ingenierías.

Finalmente, en el Congreso se aprobó el despacho tendiente a que el Comité Permanente gestione la inclusión de nociones elementales de urbanismo en la enseñanza primaria, secundaria y especial; que promueva la fundación de institutos nacionales de urbanización, anexos a las universidades nacionales, destinados a la enseñanza, la investigación, el asesoramiento de los poderes públicos y el estudio de la legislación básica concerniente al urbanismo; que recomiende que en las Escuelas de Arquitectura se haga mención del elemento urbanístico como factor siempre presente en la composición arquitectónica $y$, finalmente, que gestione la formación de museos y bibliotecas urbanológicas en las poblaciones de importancia.

Alcides Greca señaló en varias oportunidades la necesidad de abordar esta problemática compleja desde las diversas disciplinas que podrían tener interés en su gestión. Al respecto, escribió que los problemas del surgimiento de las grandes ciudades estaba destinado "a la ciencia del urbanismo, cuyo campo de acción es tan amplio que podría decirse que abarca todas las ciencias conocidas, desde la meteorología hasta el derecho, desde las matemáticas hasta la sociología" (Greca, 1936a, p. 77).

Asimismo propuso la posibilidad de una gestión multidisciplinar a través de un órgano extra-facultades:

la creación del Instituto de Altos Estudios Urbanos, que se constituiría con profesores e investigadores de las diversas facultades de la Universidad. Este Instituto tendría la misión de desarrollar un plan de estudios y de investigaciones sobre problemas municipales, acordando títulos de urbanista o perito especializado en las materias relacionadas con la edilidad. Sus poseedores serían las personas indicadas para actuar con eficacia en el gobierno de nuestras ciudades y villas, aportando ciencia, orden y método en la caótica administración de los municipios. (Greca; 1937, p. 9) 
Es posible trazar una asociación entre el perfil intelectual de Alcides Greca, en tanto pretende una discusión democrática sobre los problemas urbanos que exceda el marco de la disciplina jurídica (Altamirano, 2013) y forme parte de un abordaje integral que, dando cuenta de la complejidad de estos problemas, pueda ofrecer soluciones a la gestión municipal. El otro extremo de la asociación, inevitablemente, es el contacto que Greca tiene con otros profesionales de distintas disciplinas, y particularmente el grupo ubicado en la Universidad Nacional del Litoral, en la cual estaba inscripto y que permea su visión de la problemática urbanística hasta el punto de hacer parecer inevitable un abordaje multidisciplinar ${ }^{8}$.

El desarrollo de la problemática urbanística desde un enfoque multidisciplinario aparece como una de las causas de que la misma no tenga entidad como materia de grado dentro del ámbito de la FCJS. Esta afirmación se basa en que las nociones básicas de urbanismo se incluían en un programa general de Derecho Municipal y Comparado, lo cual llevó a que el conocimiento jurídico sólo se manifestara como gestor del interés gubernamental en cuestiones atinentes a la ciudad. No obstante ello, se verifica una relevancia inusual de la temática, dada por las reuniones científicas organizadas y a las cuales asistían representantes de otras unidades académicas; y por una producción jurídica fundamentalmente elaborada por Greca y Lo Valvo que constituye la simiente del Derecho Urbanístico en Argentina.

\section{La materialización del aporte de Alcides Greca en los programas curriculares}

En este apartado se procura comparar los contenidos de los programas de los cursos Derecho Municipal y Comparado y Derecho Público Provincial y Municipal a fin de dar cuenta de la naturaleza de las mutaciones ocurridas en el período analizado y verificar la consecuencia de las mismas en relación con la adenda de la asignatura primeramente nombrada a Derecho Público Provincial. Primeramente se compararán tres programas históricos, a fin de visualizar las mutaciones en la época estudiada. En un segundo momento se realizará el cotejo de los contenidos de estos programas históricos con los contenidos actualmente tratados por el Derecho Urbanístico. Ello posibilitará concluir si efectivamente había un tratamiento relevante de las temáticas de Derecho Urbanístico a pesar de no existir una asignatura que lleve este nombre. Por último, se confrontarán los programas históricos con la obra de Greca. Esto último revelará su influencia en la redacción de los programas.

Consultando algunas obras actuales que configuran manuales para el estudio de la materia Derecho Urbanístico ${ }^{9}$, puede observarse que los temas fundamentales del área son: origen y evolución del derecho urbanístico; fuentes normativas del derecho urbanístico; distribución de competencias; los principios del derecho urbanístico; la administración pública y sus potestades en materia urbanística; los instrumentos de gestión - planes, esquemas de coherencia, cartas municipales, etc. -; régimen del suelo;

\footnotetext{
${ }^{8}$ En el texto Influencia del urbanismo en las costumbres, Greca realiza una enumeración de cuestiones referentes a la planificación urbana (distribución de espacios verdes, aprovechamiento del agua, fomento del turismo, espacios públicos como clubes y gimnasios, distribución de la vivienda y arte en espacios públicos, entre otros) que necesariamente ante la posibilidad de su regulación requieren una intervención multidisciplinar.

${ }^{9}$ Entre otros pueden mencionarse Droit de l'urbanisme de Bernard Drobenko, Paris: Gualino, 2006; Curso de derecho urbanístico de Adriana Taller; Analía Antik, Santa Fe: Rubinzal-Culzoni, 2011 y Derecho urbanístico de Fernández Ruiz, Jorge y Rivera Hernández, Juan. México: Unam, 2011, México. 
instrumentos financieros de gestión: expropiación, incentivos fiscales, etc; loteamientos; control administrativo de la utilización del suelo y el procedimiento administrativo; responsabilidad patrimonial de la administración pública; permisos de construcción; servicios públicos entre los más destacados. Esta clasificación será útil al momento de evaluar la extensión de los contenidos de urbanismo en los programas que se analizarán.

Por su parte, Alcides Greca expresó su posición indicando, como instituciones jurídicas del urbanismo a la expropiación, las servidumbres públicas, las restricciones al dominio, algunas de orden financiero, y la socialización de la tierra (Greca, 1936a, p.103).

La presente investigación tropezó con la inexistencia de documentación en los archivos públicos. Se recuperaron sólo tres programas que se utilizarán de muestrario de los contenidos que incluía el curso de Derecho Municipal comparado a fin de someter a examen los mismos y delinear, con estos límites la evolución de los contenidos de la materia. En concreto se ha analizado el Programa de 1922; el de 1950, y por contraposición conforme las consideraciones del apartado anterior, el programa de Derecho Público Provincial y Municipal Comparado de $1967^{10}$.

De la comparación entre los dos primeros y el último surge, a primera vista, que la unión del Derecho Municipal Comparado a la materia Derecho Público Provincial ha implicado la subsunción de los contenidos que en 1922 y 1950 estaban desarrollados en 14 y 21 unidades respectivamente, a ocho unidades. Esto, evidentemente, implicará el abandono de algunos temas y la unificación de otros en una sola unidad.

El programa de 1922 podría ser calificado como aquél de la Organización del Gobierno Municipal. El mismo se limita a desarrollar los ámbitos administrativos del municipio - autonomía, gobierno, organización, servicios, régimen económico y jurídico - y agrega una noticia histórica y de derecho comparado, haciendo hincapié en la importancia de la autonomía proclamada en el art. 5 de la Constitución Nacional.

El programa de 1950 es mucho más extenso, no sólo por la cantidad de unidades, sino también por las temáticas que desarrolla en cada una de ellas y la amplitud de las mismas. Si bien los programas de las asignaturas no llevan el nombre de sus autores, se verificará más adelante que la inclusión de nuevas temáticas muy sesgadas por contenidos urbanísticos podría pertenecer a la pluma de Alcides Greca. Se incluyen unidades sobre los factores determinantes del crecimiento urbano, la enseñanza y aplicación del urbanismo, la organización de los poderes municipales - incluyendo temas como el voto femenino, la elección popular de los concejos, los métodos de democracia directa, entre otros -; servicios públicos y municipalización; cuatro unidades sobre policía municipal y una sobre funciones especiales del municipio: la que introduce temas como estética, balnearios, jardines, fomento de deportes, mercados, mataderos, depósitos, pesos y medidas, viviendas para empleados y obreros, etc.; separa el estudio del régimen municipal argentino en Capital Federal, jurisdicciones nacionales y regímenes provinciales.

En ambos programas se resalta una última unidad dedicada a comentar y criticar la eficacia del régimen municipal argentino y prospectivas.

${ }^{10}$ En la investigación no pudo rescatarse un programa más cercano al año 1953. Luego de algunas averiguaciones orales, se pudo determinar que no habría cambios fundamentales en los contenidos de esta asignatura entre 1953 y 1967. Esto último determinó la inclusión de este programa en la comparación, no sin antes salvar esta circunstancia.

\begin{tabular}{l|l|l} 
Hist. Educ. (Online) & Porto Alegre 21
\end{tabular}

$21 \quad$ n. 51

Jan./abr., 2017

p. $419-434$ 
En el programa de 1967 se visualiza una concentración de los temas tratados anteriormente, en unas pocas unidades, lo cual atenta con la profundidad con que pueden tratarse los mismos además de encontrarse al final del programa. Se trata, llanamente, de la desarticulación de los contenidos urbanísticos por la relevancia otorgada a los contenidos de Derecho Administrativo. Por otra parte resulta relevante la omisión de las unidades concernientes a servicios públicos y municipalización de los mismos, tema que había generado grandes polémicas en las décadas de 1930 y 1940 (Collado, 1997, p.51).

En los tres programas se mantiene la evolución histórica de la ciudad, el gobierno y la autonomía municipal; el régimen jurídico y financiero de los municipios; la evolución del régimen municipal argentino y los sistemas de organización municipal en Europa y Estados Unidos. La temática de las funciones, llamadas especiales del municipio es tratado en los tres programas analizados, aunque con distinta profundidad. En el programa de 1922 no se prevén los servicios de alumbrado, vialidad y fiscalización comercial; por su parte, el programa de 1950 es mucho más detallado en esta temática, como adelantamos. Por su parte, el programa de 1967 ciñe a sus títulos esta unidad, puesto que la amalgama con el régimen jurídico del municipio.

A fin de clarificar la comparación precedente, en el cuadro 1 se muestran los contenidos de cada uno de los programas, detallando, en las unidades más relevantes para nuestro interés, el contenido específico que abarcaban:

\section{Cuadro 1 -}

Contenido comparado de los programas de Derecho Municipal y Provincial.

\begin{tabular}{|c|c|c|c|c|c|}
\hline \multicolumn{2}{|c|}{$\begin{array}{l}\text { Programa de Derecho Municipal y } \\
\text { Comparado - año } 1922\end{array}$} & \multicolumn{2}{|c|}{$\begin{array}{l}\text { Programa Derecho Municipal y } \\
\text { Comparado - impresión } 1950\end{array}$} & \multicolumn{2}{|c|}{$\begin{array}{c}\text { Programa Derecho Público } \\
\text { Provincial y Municipal } \\
\text { Comparado - edicion oficial } \\
1967\end{array}$} \\
\hline \multirow[t]{3}{*}{$\begin{array}{l}\text { Programa de } \\
\text { Derecho } \\
\text { Municipal y } \\
\text { Comparado - } \\
\text { año } 1922\end{array}$} & $\begin{array}{l}\text { La ciudad - } \\
\text { Breve noticia } \\
\text { historica }\end{array}$ & Unidad I & $\begin{array}{l}\text { La ciudad - Origen de } \\
\text { las ciudades. }\end{array}$ & \multirow{3}{*}{ Unidad XVIII } & $\begin{array}{l}\text { La ciudad. } \\
\text { Concepto y } \\
\text { definicion. } \\
\text { Origen. }\end{array}$ \\
\hline & & Unidad II & $\begin{array}{l}\text { El urbanismo } \\
\text { Factores } \\
\text { determinantes del } \\
\text { crecimiento urbano. }\end{array}$ & & \\
\hline & & Unidad III & $\begin{array}{lr}\text { Enseñanza } & \text { y } \\
\text { aplicación } & \text { del } \\
\text { urbanismo } & \end{array}$ & & El urbanismo. \\
\hline Unidad III & $\begin{array}{l}\text { Gobierno } \\
\text { municipal - } \\
\text { Necesidad y } \\
\text { naturaleza del } \\
\text { gobierno } \\
\text { municipal. }\end{array}$ & Unidad IV & El gobierno municipal. & \multirow[t]{2}{*}{ Unidad XIX } & \multirow{2}{*}{\begin{tabular}{|l|} 
El municipio. \\
Concepto y \\
definicion. \\
Origen \\
evolucion \\
historica. \\
Aunotomia \\
municipal. \\
\end{tabular}} \\
\hline Unidad II & $\begin{array}{l}\text { Autonomia } \\
\text { Municipal }\end{array}$ & Unidad V & Autonomia. & & \\
\hline Unidad IV & $\begin{array}{l}\text { Organización } \\
\text { municipal - } \\
\text { Sistemas, tipos. }\end{array}$ & Unidad VI & $\begin{array}{l}\text { Organización de los } \\
\text { poderes municipales }\end{array}$ & & \\
\hline Unidad X & $\begin{array}{l}\text { Régimen jurídico } \\
\text { del municipio }\end{array}$ & Unidad VII & $\begin{array}{l}\text { Régimen Jurídico del } \\
\text { Municipio }\end{array}$ & Unidad XXIII & $\begin{array}{l}\text { Régimen jurídico } \\
\text { del municipio. }\end{array}$ \\
\hline
\end{tabular}




\begin{tabular}{|c|c|c|c|c|c|}
\hline Unidad IX & \begin{tabular}{|l} 
Régimen \\
económico y \\
financiero.
\end{tabular} & Unidad VIII & Régimen Financiero. & Unidad XXV & \begin{tabular}{|l} 
Régimen \\
financiero \\
municipal.
\end{tabular} \\
\hline Unidad VIII & $\begin{array}{l}\text { Municipalización } \\
\text { de los servicios. }\end{array}$ & Unidad IX & Los servicios públicos. & & \\
\hline Unidad VII & $\begin{array}{l}\begin{array}{l}\text { Administración } \\
\text { municipal. }\end{array} \\
\end{array}$ & Unidad X & Municipalización. & & \\
\hline Unidad VI & $\begin{array}{l}\text { Función del } \\
\text { municipio. }\end{array}$ & Unidad XI & $\begin{array}{l}\text { Funciones especiales } \\
\text { del municipio. }\end{array}$ & Unidad XXIII & \begin{tabular}{|lr}
$\begin{array}{l}\text { Funciones } \\
\text { servicios }\end{array}$ & $y$ \\
especiales & del \\
municipio. & \\
\end{tabular} \\
\hline & & Unidad XII & Polícía municipal. & \multirow{4}{*}{ Unidad XXIV } & \multirow{4}{*}{$\begin{array}{l}\text { Policía } \\
\text { municipal. }\end{array}$} \\
\hline & & unidad XIII & $\begin{array}{l}\text { Policía de los sitios } \\
\text { públicos. }\end{array}$ & & \\
\hline & & Unidad XIV & Policía de costumbres. & & \\
\hline & & Unidad XV & $\begin{array}{l}\text { La asistencia social en } \\
\text { el municipio. }\end{array}$ & & \\
\hline Unidad XI & $\begin{array}{l}\text { Régimen } \\
\text { municipal } \\
\text { argentino- } \\
\text { Breve noticia } \\
\text { histórica }\end{array}$ & \multirow{2}{*}{ Unidad XVI } & \multirow{2}{*}{$\begin{array}{lr}\text { Régimen } & \text { municipal } \\
\text { argentino. } & \text { Breve } \\
\text { noticia } & \text { histórica. } \\
\text { Régimen de la Capital } \\
\text { Federal. }\end{array}$} & \multirow{3}{*}{ unidad XX } & \multirow{3}{*}{$\begin{array}{l}\text { Régimen } \\
\text { municipal } \\
\text { argentino. Breve } \\
\text { noticia histórica. } \\
\text { El gobierno de la } \\
\text { Capital Federal. } \\
\text { El régimen } \\
\text { municipal en los } \\
\text { territorios } \\
\text { nacionales. }\end{array}$} \\
\hline Unidad XIII & \begin{tabular}{|l|} 
Régimen \\
municipal de la \\
Ciudad de \\
Buenos Aires \\
\end{tabular} & & & & \\
\hline \multirow[t]{2}{*}{ Unidad XII } & \multirow{2}{*}{$\begin{array}{l}\text { Rëgimen } \\
\text { municipal } \\
\text { argentino - } \\
\text { Caracteres } \\
\text { generales de la } \\
\text { organización del } \\
\text { gobierno } \\
\text { municipal en las } \\
\text { provincias y } \\
\text { territorios } \\
\text { federales. }\end{array}$} & $\begin{array}{l}\text { Unidad } \\
\text { XVII }\end{array}$ & $\begin{array}{l}\text { Regímenes } \\
\text { municipales vigentes } \\
\text { en el país. Jurisdicción } \\
\text { nacional }\end{array}$ & & \\
\hline & & $\begin{array}{l}\text { Unidad } \\
\text { XVIII }\end{array}$ & $\begin{array}{l}\text { Regímenes } \\
\text { municipales de las } \\
\text { provincias. }\end{array}$ & Unidad XXI & $\begin{array}{l}\text { Regímenes } \\
\text { municipales } \\
\text { vigentes en las } \\
\text { provincias. }\end{array}$ \\
\hline \multirow[b]{2}{*}{ Unidad V } & \multirow{2}{*}{$\begin{array}{l}\text { Organización } \\
\text { municipal } \\
\text { comparada }\end{array}$} & Unidad XIX & $\begin{array}{l}\text { Organización } \\
\text { municipal en los } \\
\text { Estados Unidos }\end{array}$ & \multirow[b]{2}{*}{ Unidad XXII } & \multirow{2}{*}{$\begin{array}{l}\text { La organización } \\
\text { mnicipal en la } \\
\text { legislación } \\
\text { comparada. } \\
\text { Estados Unidos } \\
\text { de } \quad \text { Norte } \\
\text { América. } \\
\text { Europa. }\end{array}$} \\
\hline & & Unidad XX & $\begin{array}{l}\text { La organización } \\
\text { municipal en Europa }\end{array}$ & & \\
\hline Unidad XIV & $\begin{array}{l}\text { El régimen } \\
\text { muncipal } \\
\text { argentino, su } \\
\text { organización, } \\
\text { práctica y acción } \\
\text { frente a la } \\
\text { experiencia } \\
\text { extranjera. } \\
\text { comentario, } \\
\text { crítica. } \\
\text { Orientación } \\
\text { futura. } \\
\end{array}$ & Unidad XXI & $\begin{array}{l}\text { La eficacia en el } \\
\text { régimen municipal } \\
\text { argentino. }\end{array}$ & & \\
\hline
\end{tabular}


La comparación entre los contenidos de los tres programas y los que actualmente conforman el núcleo del Derecho Urbanístico arriba descripto parece ahora necesaria.

Respecto del origen y evolución del derecho urbanístico, el programa de 1922 omite este tema, tratando el origen del gobierno municipal, mientras que el programa de 1950 titula su Unidad II El Urbanismo: Factores determinantes del crecimiento urbano. Estadística comparada. El urbanismo en la antigüedad, en la edad media y en la época moderna. El urbanismo en la Argentina. Sus problemas. En este caso, los contenidos de urbanismo están explícitos y se correlacionan con aquellos tratados actualmente por la doctrina especializada. Finalmente, el programa de 1967 suprime los contenidos de esta Unidad.

El tema de las fuentes normativas del derecho urbanístico, entre las cuales pueden incluirse los principios, no es tratado en ninguno de los programas, en cambio la distribución de competencias imprime en los tres, su relevancia. Se observa una primacía de tratamiento de la organización municipal respecto de la provincial y nacional - temas como la autonomía municipal, estudios de derecho comparado, el régimen del art. 5 de la Constitución Nacional, etc. dan cuenta de la importancia de la temática -, aunque en el programa de 1922 se hace hincapié en las teorías de la autonomía realizando asimismo un estudio de derecho comparado. Por su parte, el contenido de la unidad referida a esta temática en los programas de 1950 y 1967 es idéntico en las palabras, a pesar de que las concepciones variaban mucho entre los autores ${ }^{11}$.

La administración pública y sus potestades en materia urbanística es otro punto en el cual se visualizan diferencias. Tanto el programa de 1922 como el de 1967 se limitan a proponer como objeto de estudio El municipio como sujeto de derecho tanto privado como público, sus formas de actuación y los poderes legales del municipio. En cambio, el programa de 1950, además de profundizar la enunciación de estos temas e incluir la naturaleza jurídica de las normas municipales, y su responsabilidad legal y económica incluye cinco unidades referidas a las distintas manifestaciones del poder de policía municipal - funciones especiales, policía sanitaria, de los sitios públicos, de costumbres, asistencia social -, a más de las unidades sobre servicios públicos y municipalización ya aludidas.

Por otra parte, es notoria la omisión, en los programas de 1922 y 1967 de los instrumentos de gestión, particularmente de los planes, que conforme se mencionara antes fueron el medio por excelencia por el cual el urbanismo se constituyó en un saber de Estado. En este sentido, sería posible justificar su ausencia del programa de 1922, época en la cual aún no se había consolidado tal saber, pero no así en el otro programa. Es importante destacar que en el programa de 1950 el tema está tratado en la unidad Enseñanza y aplicación del urbanismo, en el cual se incluye como aplicación del urbanismo en la Argentina a los Planes reguladores y las leyes y ordenanzas al respecto. Junto a esto, también se nota la ausencia de tratamiento del régimen del suelo. Si bien en el programa de 1950 hay algunos temas dentro de la Unidad XI: Funciones especiales del

\footnotetext{
${ }^{11}$ Greca era un defensor a ultranza de la autonomía municipal en todos los aspectos, fundamentándose en el art. 5 de la Constitución Nacional (Greca, 1943). Por su parte, Bielsa, hacía una interpretación de dicho artículo limitando la autonomía municipal a la elección de autoridades y jurisdicción sobre los servicios y prestaciones exclusivamente territoriales (Bielsa, 1940).

\begin{tabular}{|l|l|l|l|l|l|}
\hline Hist. Educ. (Online) & Porto Alegre & v. 21 & n. 51 & Jan./abr., 2017 & p. 419-434
\end{tabular}
}


municipio tales como Vialidad. Pavimentaciones y desagües. Caminos de acceso. Aceras. Playas de estacionamiento. Viviendas para empleados y obreros. Barrios. Jardín, que podrían encuadrar dentro del régimen general de uso del suelo, no existe un tratamiento sistemático del mismo.

Los instrumentos financieros de gestión no son tratados como tales en los programas, a pesar de que en los tres se aborda la temática del régimen financiero del municipio. No obstante, en todos los casos la óptica es impositiva, incursionando en la autonomía financiera y en los tipos de imposiciones que los municipios pueden crear.

El loteamiento y control administrativo del uso del suelo no son temas presentes en los programas analizados. Por su parte, el procedimiento administrativo es tratado bajo el título Régimen jurídico del municipio, aludiendo en 1950 y 1967 a elementos de la teoría general del derecho administrativo: actos discrecionales y reglados, validez de las ordenanzas, poder de policía. En cambio, el programa de 1922 refiere a la gestión directa o indirecta de las funciones del municipio.

Finalmente, sobre la temática de los servicios públicos, se indicó ya que en el programa de 1922 el tema se trata bajo el sesgo de la municipalización de los servicios públicos y sus ventajas/desventajas. En el programa de 1950 se dedican dos unidades al tema - Unidad IX y X - que diferencian las generalidades de los servicios públicos y los sistemas de prestación, la primera y la municipalización la segunda. No obstante, en otras Unidades se trata la potestad regulatoria del municipio sobre el transporte y alumbrado entre otros ${ }^{12}$.

Finalmente resta comparar los programas, particularmente aquél de 1950, con los textos académicos producidos por Alcides Greca, para revisar aquella afirmación de que el programa mencionado no tiene, pero parece tener su firma.

En primer lugar, dicho programa de 1950 incluye una unidad sobre El urbanismo, y también una sobre la enseñanza y aplicación del urbanismo en la cual se trasluce la preocupación que manifestó Greca en sus trabajos sobre la existencia de una ciencia del urbanismo y la teorización del mismo en Argentina. A ello debemos agregar que los contenidos de esta unidad están extensamente tratados en el Tomo I de Derecho y ciencia de la administración municipal, en el cual se encuentra desarrollado el tema de la enseñanza del urbanismo en los capítulos $\mathrm{V}$ y VI.

Por otra parte, los contenidos del programa relativos a las Unidades IX y X, relativos a los servicios públicos y su posible municipalización, son tratados en el Tomo III de Derecho y ciencia de la administración municipal, Libro octavo, cuyo índice de los capítulos I y II se corresponde textualmente con los temas abarcados por el programa. Además de ellos, trata en otros capítulos El sistema de economía mixta en los servicios públicos, Los servicios urbanos, Las tarifas en los servicios público" y El privilegio en los servicios públicos.

Los contenidos de las Unidades XI a XV, correspondientes a las funciones de los municipios, especiales y el poder de policía son tratados en el Tomo II de Derecho $y$ Ciencia de la Administración Municipal, libro tercero, capítulos i a iv y libro cuarto, capítulo I. Nuevamente se verifica una identidad casi exacta entre los temas del libro y el programa.

${ }^{12}$ Se incluyen aquí calefacción y fuerza motriz. Hist. Educ. (Online) Porto Alegre

v. 21

ก. 51

Jan./abr., 2017 p. $419-434$ 
Del análisis precedente puede visualizarse una impronta otorgada por la figura de Alcides Greca, intelectual que percibió los problemas urbanos y que los tradujo al lenguaje jurídico a partir de lo que hoy conocemos como derecho urbanístico. En tal sentido, si bien no desarrolló todos los temas que hoy conforman el área, la huella dejada en el programa de 1950 como así también su correlación con los temas tratados en su producción académica dan cuenta de la relevancia de este personaje en la inclusión y circulación de estos contenidos. Los mismos fueron perdiéndose a raíz de la concentración del programa por la fusión de las asignaturas Derecho Municipal Comparado y Derecho Público Provincial, perdiendo la primera gran parte de los contenidos que se observan en el programa de 1950.

Relacionado a ello, indiquemos que a la época en que se produjeron las modificaciones en el plan de estudios de la Facultad de Ciencias Jurídicas y Sociales (1953) y, consecuentemente en los programas de las materias, el Dr. Greca ya se encontraba radicado en la ciudad de Rosario y había renunciado a sus cargos en la Facultad.

\section{Algunas reflexiones finales}

El aporte que realizó Alcides Greca en la FCJS provino de una inquietud nacida de su formación como abogado y su compromiso con la comunidad ciudadana en la cual estaba inserto. Los problemas urbanos que comenzaban a manifestarse a comienzos del siglo 20 no le eran ajenos. La propuesta para su gestión fue permeada por su carácter intelectual y su relación con un grupo de expertos que abordaban la temática desde diversas disciplinas. Ambas características son relevantes a la hora de precisar su actuación en la FCJS.

En el ámbito académico, su relación con otros profesionales que abordaban la problemática urbanística, dará un perfil particular al interés por insertar esta temática en la currícula de grado. Como profesor del curso Derecho Municipal Comparado buscará introducir en el programa de dicha materia las áreas temáticas esenciales que conformarían el derecho urbanístico. La introducción de las mismas es precedida por su elaboración, la que se manifiesta en la obra jurídica de Greca. Ya como director de la Revista de la Facultad de Ciencias Jurídicas y Sociales y acompañado por el Decano de la Facultad, José Lo Valvo, realizan la Primera Semana del Urbanismo (1936), la cual da como fruto dos números de la revista en los que se vuelcan artículos de autores provenientes de distintas disciplinas.

A ello se agregan una serie de trabajos de Alcides Greca que se publicarán como artículos tanto en la Revista mencionada como para la Revista Universidad y otras publicaciones externas ${ }^{13}$. Este acervo se consolidará hacia fines de la década de ' $30 \mathrm{y}$ comienzos de la del ' 40 con dos publicaciones en forma de libro Problemas del urbanismo en la República Argentina y Derecho y ciencia de la administración municipal.

\footnotetext{
${ }^{13}$ Nos referimos, concretamente a La ciencia del urbanismo, en Revista Universidad, n. II, Santa Fe, jul. 1936; La enseñanza del urbanismo en la Universidad Nacional del Litoral, en Revista de la Facultad de Ciencias Jurídicas y Sociales, año II, n. 21-22, Santa Fe, 1937; Influencia del urbanismo en las costumbres, en Revista de Derecho y Administración Municipal, tomo IX, n. 74, Buenos Aires, abr. 1936, p. 26-28.
} 
El carácter intelectual de Greca, demostrado en el ámbito académico a partir de una serie de discursos y de su producción escrita, da cuenta de su interés en concebir a la abogacía puesta en función social ${ }^{14}$. En la problemática urbanística, manifiesta este carácter otorgando al Derecho la misión de señalar el camino del urbanista: "Los planes más bellos y atrevidos no son factibles cuando se apartan de la realidad. La fantasía puede llevar muy lejos a un urbanista emprendedor [...] pero el derecho le señala el camino y las finanzas los recursos para llegar a la meta" (Greca, 1936b, p. 28). La concepción del urbanismo como una disciplina llamada a ser henchida de conocimientos diversos, a partir de los cuales se puedan producir soluciones a los problemas de las urbes, constituye el mejor ejemplo del compromiso del autor con los mismos.

Su importante aporte a la construcción del derecho urbanístico en la FCJS tuvo un momento de apogeo en las décadas del 1930 y 1940, pero al no institucionalizarse en una asignatura, ni disponer de un albacea, su legado no sólo no se mantuvo en el programa y en la producción académica, sino que fue lamentablemente olvidado.

\section{Bibliografía}

ALTAMIRANO, Carlos. Intelectuales: notas de investigación sobre una tribu inquieta, Buenos Aires: Siglo XXI, 2013.

BIELSA, Rafael Principios de régimen municipal. Santa Fe: Universidad Nacional del Litoral, 1940.

COLLADO, Adriana. La defensa de los intereses ciudadanos en la intendencia de Agustín Zapata Gollan. Santa Fe 1932-1934. Separata de la revista America, n. 13, 1997, p. 45-65.

DROBENKO, Bernard. Droit de I'urbanisme. Paris: Gualino, 2006.

FERNANDEZ RUIZ, Jorge; RIVERA HERNÁNDEZ, Juan. Derecho urbanístico. México: Unam, 2011.

GRECA, Alcides. La ciencia del urbanismo. Revista Universidad, Santa Fe: UNL, n. II, 1936a, p. 77-106.

GRECA, Alcides. Influencia del urbanismo en las costumbres. Revista de Derecho y Administración Municipal, Buenos Aires, tomo IX, n. 74, 1936b, p. 26-28.

GRECA, Alcides. La enseñanza del urbanismo en la Universidad Nacional del Litoral. Revista de la Facultad de Ciencias Jurídicas y Sociales. Santa Fe: UNL, año II, n. 21-22, 1937, p. 5-12.

GRECA, Alcides. Un mensaje a la juventud universitaria. Rosario: Talleres Gráficos Emilio Fenner, 1938.

LEFEVBRE, Henry. El derecho a la ciudad. Barcelona: Península, 1968.

RIGOTTI, Amanda Las promesas del urbanismo como alternativa tecnocrática de gestión (1928/1958) In: BEN PLOTKIN, Martin (ed.). Los saberes del Estado. Buenos Aires: Edhasa, 2012.

\footnotetext{
${ }^{14}$ Al respecto es interesante la postura sostenida en Un mensaje a la juventud universitaria (1938) en el que bregaba porque la reforma universitaria saliera a la calle y Tragedia espiritual de los argentinos que hoy tienen 20 años. En este último texto indicaba que una de las dos tragedias que afectaban a la juventud era la carencia de un ideario político-social, claro y definido, que contemple nuestro momento histórico y los verdaderos problemas del país (Greca, 1938). 
SANCHEZ, Alberto. Del derecho a la vivienda al derecho a la ciudad. Observatorio Derechos Económicos, Sociales y Culturales. (S/F). En línea <http://www.descweb.org $>$. Consulta en 13 oct 2012.

SOTOLONGO CODINA Pedro; DELGADO DÍAZ, Carlos, La revolución contemporánea del saber y la complejidad social. Hacia unas ciencias sociales de nuevo tipo. Buenos Aires: Clacso, 2006.

SOZZO Gonzalo. José Lo Valvo o los intelectuales como arquitectos institucionales, manuscrito inédito del autor, 2012.

TALLER, Adriana; ANTIK, Analía. Curso de derecho urbanístico. Santa Fe: RubinzalCulzoni, 2011.

NORMA ELIZABETH LEVRAND es abogada, especialista en Derecho Laboral, y becaria doctoral del Consejo Nacional de Investigaciones Científicas y Técnicas de Argentina. Es docente adjunta interina del Seminario de Relaciones Laborales de la carrera de licenciatura en Administración Pública de la Universidad Autónoma de Entre Ríos y jefa de trabajos prácticos de la materia Ciencia, Tecnología y Sociedad de las carreras de Ingeniería en Informática y Agrimensura de la Universidad Nacional del Litoral.

Dirección: Cándido Pujato 2751, 1er. piso, Ala Oeste - Santa Fe - 3100 - Provincia de Santa Fe - Argentina.

E-mail: nlevrand@fcjs.unl.edu.ar.

Recebido em 14 de março de 2016.

Aceito em 22 de agosto de 2016. 